\title{
Exercises Responses of 60-69 Years on the Senior Fitness Test in Jordan Compared to US Norms
}

\author{
Harran Al-Rahamneh ${ }^{1}$, Khawla Yousef $^{1} \&$ Wafa' $^{\prime}$ ssmail $^{1}$ \\ ${ }^{1}$ Faculty of Physical Education, the University of Jordan, Amman, Jordan \\ Correspondence: Harran Al-Rahamneh, Faculty of Physical Education, The University of Jordan, P.O.Box: \\ 13366, Amman 11942, Jordan. E-mail: h.rahamneh@ju.edu.jo
}

Received: July 12, 2015 Accepted: July 28, 2015 Online Published: August 18, 2015

doi:10.5539/ass.v11n24p343

URL: http://dx.doi.org/10.5539/ass.v11n24p343

\begin{abstract}
Introduction: It is well established that most body functions are affected by ageing. Regular physical activity reduces the risk of heart diseases, type 2 diabetes, osteoporosis and enhance the well-being among elderly. Therefore, this study assessed exercise responses in 60-69 year-olds Jordanian to the Senior Fitness Test in comparison to the US norms.

Methods: Sixty eight men (mean $\pm \mathrm{SD}, 67.1 \pm 4.6 \mathrm{y})$ and 54 women $(63.3 \pm 3.5 \mathrm{y})$ from local society volunteered for the study. Each person performed six exercise tests of the senior fitness test; 30 -second chair stand test; 30-Second arm curl test; Chair sit and reach test; Back scratch test; 8-Foot up and go exercise test and 6-Minute walk test.

Results: Low values of 8-Foot up and go exercise test, back scratch test and 6-Minute walk test for women compared to the US norms. Good and comparable values of 30-second chair stand test, 30-Second arm curl test and Chair sit and reach test compared to the US norms.

Discussion: The low values of 8-Foot up and go exercise test and back scratch test may be attributed to the fact that these type of exercise are not very common in the daily activity of elderly in Jordan. However, the good results of chair sit and reach exercise test is essential part of their daily physical activity especially during the prayer time, which they have to do five times a day.
\end{abstract}

Keywords: exercise responses, senior fitness test, Elderly, US norms

\section{Introduction}

Functional performance within the body is decreased due to aging (Skinner, 2005). Physiological adaptations to the stimuli of training are also affected with aging (Skinner, 2005; Taylor \& Johnson, 2008). The prevalence of chronic diseases and disabilities and the cost of health care services are high among those above 65 years old (Berg \& Casells, 1990; Jackson et al., 1999; Taylor \& Johnson, 2008). At age of 30 people start to gain weight by $0.5 \mathrm{~kg}$ each year and this increase is in body fat (Wilmore et al., 2008). Kohrt et al. (1992) reported higher fat mass in trained and sedentary older individuals compared to trained and sedentary young persons and this was evident for both males and females. Bone mass density (BMD) starts to decline after the age of 35 year for both men and women and this reduction in BMD increases after the age of 50 years for men and after the menopause for women (Smith et al., 2009). Osteoporosis leads to fractures and hip and femoral neck are the most serious fractures (Smith et al., 2009). 24\% of individuals with hip fracture above 50 years old will die within the first year (Smith et al., 2009).

Muscle mass is reduced with ageing and this can be due to the reduction in the size and number of muscle fibres (Roger \& Evans, 1993; Evans, 1995). This reduction in muscle mass will lead to a reduction in strength. In fact, research has shown that individuals lose $1.5 \%$ per year of their strength between $50-70 \%$ years old and $3 \%$ after the age of 70 years old (ACSM,1998). The loss of lean body mass will also lead to a reduction in basal metabolic rate (Evans, 1995). Aerobic capacity is also decreased with age (ACSM, 1998). Heath et al. (1981) has indicated that there is a reduction of $1 \%$ per year for healthy sedentary persons and by 0.5 for endurance-trained persons in maximal oxygen uptake. This reduction in aerobic capacity may be attributed to the reduction in maximal heart rate and maximal stroke volume (Heath et al., 1981; Wilmore et al., 2008) and in extraction of oxygen by the exercising muscles (Heath et al., 1981). Physical activity also declines with aging (Elia et al., 2000; Al-Nozha et 
al., 2007) and low physical fitness level are common among older population (Bouchard et al., 2007).

Physical fitness is the ability to perform your daily tasks with energy and having less chance to develop chronic diseases (Jackson et al., 1999). The senior fitness test was developed to be a suitable physical fitness battery to test older individuals (Rikli \& Jones, 2013). The senior fitness test includes muscular strength, aerobic endurance, flexibility, agility and dynamic balance and body mass index. Lower body strength and upper body strength are needed in many daily life activities such as walking and lifting groceries (Rikli \& Jones, 2013). Aerobic endurance is also essential for many daily life activities such as shopping and sightseeing. Low flexibility and lost range of motion may affect many functions such as bending, reaching and walking (Holland et al., 2002). Maintaining lower back flexibility has a very important role in good gait and preventing the risk of falling (Brown \& Rose, 2005). Agility and dynamic balance are very important in many daily tasks such as getting on and off buses and going to the bathroom (Rikli \& Jones, 2013). With regard to BMI and body composition, it is well established that higher percentage of body fat especially in the abdomen is correlated with type 2 diabetes, hypertension, strokes and coronary heart diseases (National Institute of Health, 1985; Wilmore et al., 2008; ACSM, 2010).

The individuals' life span has increased worldwide. The life span of the US individuals' has increased from less than 48 years old for men and women in 1900 to 73 and 79 years old in 1996 for men and women, respectively (Jackson et al., 1999). The life span of Jordanian population has increased from 67 years old for both genders in 1990 to 72 and 77 years old in 2012 for men and women, respectively (The Jordanian Department of Statistics, 2012). That means the population of old persons have expanded especially those above 60 years old in Jordan. Therefore, the aim of the current study was to assess the exercise responses, physical fitness level, of 60-69 years old individuals on the senior fitness test compared to the US norms for the same age range.

\section{Methods}

\subsection{Participants}

Sixty eight men (mean \pm SD for age, height and weight $=67.1 \pm 4.6 \mathrm{y} ; 168.1 \pm 8.0 \mathrm{~cm}, 81 \pm 12.8 \mathrm{~kg}$, respectively) and 54 women (mean $\pm \mathrm{SD}$ for age, height and weight $=63.3 \pm 3.5 \mathrm{y}, 155.7 \pm 6.1 \mathrm{~cm}, 75.4 \pm 12.5$ $\mathrm{kg}$, respectively) from local society volunteered for the study. Inclusion criteria were: 1) provided informed consent to take part in the study; 2) his/her age between 60-69 years old;3) be able to perform the elements of the senior fitness test; 4) passed the physical activity readiness questionnaire (PAR-Q) successfully. All the instructions with regard to the PAR-Q were followed as described in the (ACSM, 2010). This study was conducted in accordance with institutional ethics approval from the Faculty of Physical Education at the University of Jordan.

\subsection{Procedures}

On arrival, body mass was measured for each person to the nearest $0.1 \mathrm{~kg}$ and height was also measured for each person to the nearest $0.5 \mathrm{~cm}$ while standing barefoot, wearing very light clothes (Seca weight-height Scale, Hamburg, Germany). BMI is weight in kilograms divided by height in meters squared, (BMI = weight $(\mathrm{kg})$ / height $\left(\mathrm{m}^{2}\right)$ ) was calculated for each person.

Proper warming-up and stretching exercises were delivered by the researchers in order to prepare and enhance physical and psychological status of participants to the exercise tests and to prevent injuries. Each person performed six exercise tests which are involved in the senior fitness test. These exercise tests are: 1. 30-second chair stand test; 2. 30-Second arm curl test; 3. Chair sit and reach test; 4. Back scratch test; 5. 8-Foot up and go exercise test; 6. 6-Minute walk test. The first five exercise tests performed in a random order but the 6-Minute walk exercise test performed last in order to prevent its effect on the other five exercise tests. On completion, cool down exercises were delivered to each person in order to prevent injuries and making sure that everything is Ok with each person before leaving the testing area.

\subsection{Exercise Tests}

These are the six exercise test performed as described in Rikli \& Jones, (2013).

\subsubsection{0-Second Chair Stand Test}

The aim of this exercise test is to assess lower body strength. Lower body strength is needed in many daily life activities such as walking and climbing stairs. From a seated position, each participant was asked to do as much of full stands he/she can do in 30 seconds while the arms were folded on the chest (Jones et al., 1999).

\subsubsection{0-Second Arm Curl Test}

The aim of this exercise test is to assess upper body strength. Upper body strength is needed in many daily life 
activities such as carrying suitcases and groceries. From a seated position and while carrying 8 pounds for men and 5 pounds for women, the number of biceps curl will be counted in 30 seconds (Rikli \& Jones, 2013).

\subsubsection{Chair Sit and Reach Test}

The aim of this exercise test is to assess lower body flexibility. Lower body flexibility is important in activities such as getting out of the car, having good posture and having a normal gait. Each participant was asked to extend his/her leg and to bend the other around 90 degrees. With the palms on top of each other the participants were asked to reach as far distance as he/she can and the distance between the fingertip and the toes (plus or minus) was recorded (Jones et al., 1998). If the fingertips just touches the toes that is recorded as 0 , if exceeds that is recorded as plus and if do not reach each other that is recorded as minus.

\subsubsection{Back Scratch Test}

The aim of this exercise test is to assess upper back and shoulders flexibility. Upper back and shoulder flexibility is needed in many activities such as putting thing in the upper shelves and reaching seat belts. The distance between the arms when one extended over the shoulder and the other on the middle of the back was recorded (Rikli \& Jones, 2013). If the fingertips of both arms are touched that is recorded as 0 , if exceeds that is recorded as plus and if do not reach each other that is recorded as minus.

\subsubsection{8-Foot Up and Go Exercise Test}

The aim of this exercise test is to assess agility and dynamic balance. Agility and dynamic balance are needed in many daily life activities such as going to bathroom, answering the phone and crossing the road. The time it takes to get up from a seated position and walk 2.4 meter and returned back to the seated position was recorded (Rikli \& Jones, 2013).

\subsubsection{6-Minute Walk Test}

The aim of this exercise test is to assess cardiorespiratory fitness level and aerobic endurance. Cardiorespiratory fitness is important in our daily life activities such as walking, shopping and sightseeing (Rikli \& Jones, 2013). The number of meters walked/ran in 6 minutes around a handball court was recorded.

\subsection{Data Analysis}

Percentiles were used to determine the percentile norms for 30-second chair stand test, 30-second arm curl test, chair sit and reach test, back scratch test, 8-foot up and go exercise test and 6-minute walk test for men and women. All data were analyzed using the Statistical Package for Social Sciences (SPSS) for Windows, PC software, version 21.

\section{Results}

Percentile norms of the senior fitness elements (i.e., 30-second chair stand test, 30-second arm curl test, chair sit and reach test, back scratch test, 8-foot up and go test and 6-minute walk test) for men and women are presented in Table 1 and Table 3.

Table 1. Shows Jordan percentile norms for the Senior Fitness Test for Men $(n=68)$

\begin{tabular}{|c|c|c|c|c|c|c|}
\hline Percentiles & $\begin{array}{l}\text { 30-Second } \\
\text { chair stand test }\end{array}$ & $\begin{array}{l}\text { 30-Second arm } \\
\text { curl test }\end{array}$ & $\begin{array}{l}\text { Chair sit and } \\
\text { reach test }(\mathrm{cm})\end{array}$ & $\begin{array}{l}\text { Back scratch } \\
\text { test }(\mathrm{cm})\end{array}$ & $\begin{array}{l}\text { 8-Foot up and go } \\
\text { exercise test (s.ms) }\end{array}$ & $\begin{array}{l}\text { 6-Minute walk } \\
\text { test }(\mathrm{m})\end{array}$ \\
\hline 95 & 28 & 30 & 19 & 6 & 3.16 & 955 \\
\hline 85 & 21 & 26 & 14 & 2 & 3.64 & 827 \\
\hline 75 & 20 & 25 & 11 & -3 & 3.84 & 737 \\
\hline 65 & 18 & 23 & 6 & -9 & 4.21 & 643 \\
\hline 55 & 17 & 22 & 5 & -12 & 4.41 & 596 \\
\hline 45 & 15 & 21 & 2 & -15 & 4.50 & 545 \\
\hline 35 & 13 & 20 & 0.0 & -17 & 5.14 & 511 \\
\hline 25 & 12 & 17 & -3 & -20 & 5.75 & 452 \\
\hline 15 & 10 & 15 & -14 & -24 & 6.50 & 371 \\
\hline 5 & 8 & 10 & -21 & -30 & 8.91 & 215 \\
\hline Mean \pm SD & $16 \pm 6$ & $21 \pm 6$ & $2.3 \pm 11.7$ & $-12 \pm 11$ & $5.04 \pm 1.74$ & $587 \pm 210$ \\
\hline
\end{tabular}


Table 2. Shows US percentile norms for the Senior Exercise Test elements for Men

\begin{tabular}{ccccccc}
\hline Percentiles & $\begin{array}{c}\text { 30-Second chair } \\
\text { stand test }\end{array}$ & $\begin{array}{c}\text { 30-Second arm } \\
\text { curl test }\end{array}$ & $\begin{array}{c}\text { Chair sit and } \\
\text { reach test }(\mathrm{cm})\end{array}$ & $\begin{array}{c}\text { Back scratch } \\
\text { test }(\mathrm{cm})\end{array}$ & $\begin{array}{c}\text { 8-Foot up and go } \\
\text { exercise test (s.ms) }\end{array}$ & $\begin{array}{c}\text { 6-Minute walk } \\
\text { test (m) }\end{array}$ \\
\hline 95 & 23 & 27 & 8.0 & 4.2 & 3.05 & 813 \\
85 & 21 & 24 & 5.2 & 1.3 & 3.60 & 754 \\
75 & 19 & 22 & 3.5 & -0.5 & 4.05 & 718 \\
65 & 18 & 21 & 2.2 & -1.9 & 4.40 & 691 \\
55 & 17 & 20 & 0.9 & -3.2 & 4.70 & 665 \\
45 & 16 & 18 & -0.3 & -4.4 & 5.1 & 640 \\
35 & 14 & 17 & -1.6 & -5.7 & 5.4 & 615 \\
25 & 13 & 16 & -2.9 & -7.0 & 5.75 & 587 \\
15 & 12 & 14 & -4.6 & -8.8 & 6.2 & 551 \\
5 & 9 & 11 & -7.4 & -11.7 & 6.95 & 493 \\
\hline
\end{tabular}

Note: adapted from Rikli, RE, \& Jones, CJ (2013). Senior Fitness Test Manual. Champaign, IL: Human Kinetics.

Table 3. Shows Jordan percentile norms for the Senior Fitness Test for Women $(n=54)$.

\begin{tabular}{ccccccc}
\hline $\begin{array}{c}\text { Variables/ } \\
\text { Percentiles }\end{array}$ & $\begin{array}{c}\text { 30-Second } \\
\text { chair stand test }\end{array}$ & $\begin{array}{c}\text { 30-Second arm } \\
\text { curl test }\end{array}$ & $\begin{array}{c}\text { Chair sit and } \\
\text { reach test }(\mathrm{cm})\end{array}$ & $\begin{array}{c}\text { Back scratch } \\
\text { test }(\mathrm{cm})\end{array}$ & $\begin{array}{c}\text { 8-Foot up and go } \\
\text { exercise test (s.ms) }\end{array}$ & $\begin{array}{c}\text { 6-Minute walk } \\
\text { test (m) }\end{array}$ \\
\hline 95 & 27 & 29 & 23 & 9 & 3.78 & 695 \\
85 & 19 & 25 & 16 & 2 & 4.13 & 620 \\
75 & 17 & 23 & 12 & -5 & 4.38 & 591 \\
65 & 16 & 22 & 11 & -8 & 4.76 & 545 \\
55 & 14 & 20 & 7 & -10 & 5.06 & 456 \\
45 & 13 & 18 & 5 & -16 & 5.37 & 410 \\
35 & 12 & 16 & 3 & -19 & 5.80 & 397 \\
25 & 10 & 15 & 0.8 & -22 & 6.32 & 368 \\
15 & 9 & 13 & 0.0 & -25 & 7.24 & 287 \\
5 & 6 & 10 & -13 & -29 & 10.5 & 188 \\
Mean \pm SD & $14 \pm 6$ & $19 \pm 6$ & $6 \pm 10$ & $-13 \pm 13$ & $5.76 \pm 2.12$ & $456 \pm 151$ \\
\hline
\end{tabular}

Table 4. Shows US percentile norms for the Senior Exercise Test elements for Women

\begin{tabular}{ccccccc}
\hline $\begin{array}{c}\text { Variables/ } \\
\text { Percentiles }\end{array}$ & $\begin{array}{c}\text { 30-Second chair } \\
\text { stand test }\end{array}$ & $\begin{array}{c}\text { 30-Second arm } \\
\text { curl test }\end{array}$ & $\begin{array}{c}\text { Chair sit and } \\
\text { reach test }(\mathrm{cm})\end{array}$ & $\begin{array}{c}\text { Back scratch } \\
\text { test }(\mathrm{cm})\end{array}$ & $\begin{array}{c}\text { 8-Foot up and go } \\
\text { exercise test (s.ms) }\end{array}$ & $\begin{array}{c}\text { 6-Minute walk } \\
\text { test (m) }\end{array}$ \\
\hline 95 & 20 & 23 & 8.3 & 5.0 & 3.4 & 738 \\
85 & 18 & 21 & 6.0 & 2.8 & 4.2 & 682 \\
75 & 17 & 19 & 4.6 & 1.5 & 4.6 & 648 \\
65 & 16 & 18 & 3.6 & 0.5 & 4.9 & 622 \\
55 & 15 & 17 & 2.6 & -0.5 & 5.2 & 598 \\
45 & 14 & 16 & 1.6 & -1.5 & 5.6 & 574 \\
35 & 13 & 14 & 0.5 & -2.4 & 5.9 & 550 \\
25 & 12 & 13 & -0.5 & -3.4 & 6.2 & 524 \\
15 & 10 & 11 & -1.9 & -4.7 & 6.6 & 490 \\
5 & 8 & 9 & -4.0 & -6.7 & 7.4 & 434
\end{tabular}

Note: adapted from Rikli, RE, \& Jones, CJ (2013). Senior Fitness Test Manual. Champaign, IL: Human Kinetics. 
Table 5. Shows the prevalence of obesity, underweight and normal weight among older population in the study sample. Data are frequencies (n) and percent (\%)

\begin{tabular}{cccc}
\hline \multirow{2}{*}{ Gender/Classification } & Normal & Overweight & Obese \\
& $\mathrm{N}(\%)$ & $\mathrm{N}(\%)$ & $\mathrm{N}(\%)$ \\
\hline Men & $16(23.5)$ & $26(38.2)$ & $26(38.2)$ \\
Women & $5(9.3)$ & $18(33.3)$ & $31(57.4)$ \\
\hline
\end{tabular}

\section{Discussion}

Regular physical activity reduces the risk of heart diseases, type 2 diabetes, osteoporosis and enhance the well-being (U.S. Department of Health and Human Services, 1996; Leon, 1997; ACSM, 2010). Therefore, this is the first study in Jordan that presents national data on physical fitness level among elderly between 60-69 years. The main findings of the current study is that at a given percentile our sample have lower performance for 8-Foot up and go exercise test for both men and women compared to the US norms. These findings might be due to the fact that agility, speed and dynamic balance which are required for this exercise test are usually neglected in our gym or home-based training for young, adults and elderly in order to develop health-related fitness. In addition, old individuals may think that speed, agility and dynamic balance are not appropriate type of exercises for their age. Furthermore, this may be attributed to the fact that elderly individuals do these exercises and these activities slowly and with help such as using the handles for support.

In the back scratch test our sample's results are below the US norms with exception 95 and 85 percentile for men and 95 percentile for women. These flinging of the back scratch test are expected due to the fact that such specific stretching exercises for upper back and shoulder muscles are not often performed as part of our daily life activities. The results of the chair sit and reach exercise test are better than the back scratch test and better than most of the US norms. This may be due to the fact that all participants in the current study are Muslims and in the Islam religion we have to pray five times a day. Praying involves bending movements which help in maintaining lower back muscles and hamstring muscle flexibility.

Al-Nozha et al. (2007) reported that physical activity decrease with ageing among Saudis between $30-70$ years and that $98.1 \%$ of Saudis females and $93.9 \%$ of Saudis males were inactive. This confirms our findings of lower distances covered at a given percentile for women and at 65 percentile and below for men. We have included Al-Nozha et al. (2007) study due to the similarities between the two neighbouring countries. Our sample have better results in 30-second chair stand test and 30-second arm curl test for both men and women compared to the US norms. This might be attributed to the fact that some of the data collection took part in gyms where individuals focus mostly on upper and lower body strength during their training.

This study showed that $38 \%$ of men and $57 \%$ of women were obese and $38 \%$ of men and $33 \%$ of women were overweight. These results indicated that the prevalence of obesity and overweight among the study sample are very high. The prevalence of obesity in 2004 was $~ 25 \%$ among Canadian population between $65-74$ years old and for those older than 74 years old. The prevalence of obesity and overweight among the USA adults are $32 \%$ and $66 \%$, respectively (ACSM, 2010). These percentages of obesity and overweight in the USA are lower compared to our findings. From Al-Nozha et al. (2007) data in Saudi Arabia, $42 \%$ of men and $32 \%$ of women were overweight and $26 \%$ of men and $44 \%$ of women were obese. These percentages of obesity and overweight of Al-Nozha et al. (2007) study are similar to those of our current results on elderly Jordanians. The findings of our study may be attributed to the fact that individuals older than 60 years old in Jordan have low physical activity level, although it was not measured in the current study. To the best of our knowledge we do not have any study in Jordan which has assessed physical fitness level and physical activity level among this age range. Physical activity level is generally lower in the Eastern Mediterranean region compared to other WHO regions. Females in this region were shown to be also less active than males. Their study also showed that the percentage of inactive females was higher compared to males; this in turn may help in interpreting higher prevalence of obesity among women in the current study compared to men. Another point is that the retirement age in Jordan is 60 years old this may in turn reduce physical activity level required to accomplish a given working task.

\section{Conclusion}

This study assessed exercise responses of 60-69 years in Jordan on the senior fitness test compared to the US norms. Our sample has good results in the 30-second chair stand, 30-second arm curl and chair sit and reach exercise tests compared to the US norms. However, our sample have low responses on the back scratch and 
8-Foot up and go exercise tests compared to the US norms. Women have inferior results on the 6-minute walking test compared to the US norms. The prevalence of overweight and obesity in the current study is high. Due to lack of local literature in physical fitness and physical activity for elderly in Jordan, it is recommended that more physical activity research in the elderly Jordanian population be conducted. We also recommend extending this study in the future to include all age ranges above 60 years old (i.e., 60-95 years old) and for both genders.

\section{References}

Al-Nakeeb, Y., Lyons, M., Collins, P., Al-Nuaim, A., Al-Hazzaa, H., Duncan, M. J., \& Nevill, A. (2012). Obesity, Physical actuvuty level and sedentary behaviour amongst British and Saudi youths: a cross-cultural study. International Journal of Environmental Research and Public Health, 9, 1490-1506. http://dx.doi.org/10. 3390/ijerph9041490

Al-Nozha, M. M., Al-Hazzaa, H. M., Arafah, M. R., Al-Khadra, A., Al-Mazrou, Y. Y., \& Al-Maatouq, M. A. (2007). Prevalence of physical activity and inactivity among Saudis aged 30-70 years. Saudi Medical Journal, 28, 559-568.

American College of Sports Medicine (2010). ACSM's Guidelines for Exercise Testing and Prescription (8th ed.). Lippincott Williams \& Wilkins: Baltimore.

American College of Sports Medicine, Position stand. (1998). Exercise and physical activity for old adults. Medicine and Science in Sports and Exercise, 30, 992-308. http://dx.doi.org/10.1097/00005768199806000-00033

American College of Sports Medicine. (1998). The recommended quantity and quality of exercise for developing and maintaining cardiorespiratory and muscular fitness, and flexibility in healthy adults. Medicine and Science in Sports and Exercise, 30, 975-991. http://dx.doi.org/10.1097/00005768-199806000-00032

Berg, R. I., \& Casells, J. S. (1990). The second fifty years: promoting health and preventing disability. Washington, DC: National Academy Press.

Bouchard, C., Blair, S. N., \& Haskell, W. L. (2007). Physical activity and health. Champaign, IL: Human Kinetics.

Brown, M., \& Rose, D. J. (2005). Flexibility training. In C. J. Jones, \& D. J. Rose (Eds.), Physical activity instruction for older adults (pp. 155-174). Champaign, IL: Human Kinetics.

Elia, M., Ritz, P., \& Stubbs, R. J. (2000). Total energy expenditure in the elderly. Eur J Clin Nutr, 54(Suppl 3), S92-S103. http://dx.doi.org/10.1038/sj.ejcn.1601030

Evans, W. J. (1995). What is sarcopenia? J Gerontol A Biol Sci Med Sci, 50(Spec No), 5-8. http://dx.doi.org/10.1093/gerona/50A.Special_Issue.5

Heath, G. W., Hagberg, J. M., Ehsani, A. A., \& Holloszy, J. O. (1981). A physiological comparison of young and older endurance athletes. Journal of Applied Physiology, 51, 634-640.

Holland, G. J., Tanaka, K., Shigematsu, R., \& Nakagaichi, M. (2002). Flexibility and Physical Functions of Older Adults: A Review. Journal of Aging and Physical Activity, 10, 169-206.

Jackson, A. W., Morrow, J. R., Hill, D. W., \& Dishman, R. K. (1999). Physical Activity for Health and Fitness. Champaign, IL: Human Kinetics.

Jones, C. J., Rikli, R. E., \& Beam, W. C. (1999). A 30-s chair-stand test as a measure of lower body strength in community-residing older adults. Research Quarterly for Exercise and Sport, 70, 113-119. http://dx.doi.org/10.1080/02701367.1999.10608028

Jones, C. J., Rikli, R. E., Max, J., \& Noffal, G. (1998). The reliability and validity of a chair sit-and-reach test as a measure of hamstring flexibility in older adults. Research Quarterly for Exercise and Sport, 69, 338-343. http://dx.doi.org/10.1080/02701367.1998.10607708

Kohrt, W. M., Malley, M. T., Dalsky, G. P., \& Holloszy, J. O. (1992). Body composition of healthy sedentary and trained, young and older men and women. Medicine and Science in Sports and Exercise, 24, 832-837. $\mathrm{http}: / / \mathrm{dx}$. doi.org/10.1249/00005768-199207000-00015

Leon, A. (1997). Physical Activity and Cardiovascular Health. A national Consensus. Champaign, IL: Human Kinetics.

National Institute of Health. (1985). Health implications of obesity. Ann Intern Med, 163, 1073-7.

Rikli, R. E., \& Jones, C. J. (2013). Senior Fitness Test Manual. Champaign, IL: Human Kinetics. 
Rogers, M. A., \& Evans, W. J. (1993). Changes in skeletal muscle with aging: effects of exercise training. Exercise and sport sciences reviews, 21, 65-102. Williams and Wilkins, Baltimore. http://dx.doi.org/10.1249/00003677-199301000-00003

Skinner, J. (2005). Aging for exercise testing and exercise prescription. In J. S. Skinner (Ed.), Exercise Testing and Exercise Prescription for Special Cases: Theoretical Basis and Clinical Applications (pp. 85-99). Lippincott Williams \& Wilkins: Baltimore.

Smith, S. S., Wang, Che-Hsiang, E., \& Bloomfield, S. A. (2009). Osteoporosis. In J. L. Durstine, G. E. Moore, P. L. Painter, \& S. O. Roberts (Eds.), ACSM's Exercise Management for Persons with Chronic Diseases and Disabilities (pp. 270-279). Human Kinetics: Champaign, IL.

Taylor, A. W., \& Johnson, M. J. (2008). Physiology of exercise and healthy aging. Human kinetics: Champaign, IL.

The Jordanian Department of Statistics. (2012). The birth and death report in Jordan. Jordan: Department of Statistics.

U.S. Department of Health and Human Services. (1996). Physical Activity and Health: A report of the Surgeon General. Atlanta, GA: Centers for Disease Control and Prevention (CDC), National Centers for Chronic Disease Prevention and Health Promotion.

Wilmore, J. H., Costill, D. L., \& Kenny, D. L. (2008). Physiology of Sport and Exercise. Human kinetics: Champaign, IL.

\section{Copyrights}

Copyright for this article is retained by the author(s), with first publication rights granted to the journal.

This is an open-access article distributed under the terms and conditions of the Creative Commons Attribution license (http://creativecommons.org/licenses/by/3.0/). 